\title{
Interdisciplinary analysis of larval dispersal for a coral reef fish: opening the black box
}

\author{
C. W. W. Counsell ${ }^{1,2, *}$, R. R. Coleman ${ }^{2,3}$, S. S. Lal $^{4}$, B. W. Bowen ${ }^{2}$, E. C. Franklin ${ }^{2}$, \\ A. B. Neuheimer ${ }^{4,5}$, B. S. Powell ${ }^{4}$, R. J. Toonen ${ }^{2}$, M. J. Donahue ${ }^{2, \#}$, M. A. Hixon ${ }^{6, \# \text {, }}$ \\ M. A. McManus ${ }^{4, \#}$ \\ ${ }^{1}$ Department of Biology, College of Arts and Sciences, Fairfield University, Fairfield, Connecticut 06824, USA \\ ${ }^{2}$ Hawai'i Institute of Marine Biology, School of Ocean and Earth Science and Technology, University of Hawai'i at Mānoa, \\ Kāne'ohe, Hawai'i 96744, USA \\ ${ }^{3}$ Department of Biology, University of Central Florida, Orlando, Florida 32816, USA \\ ${ }^{4}$ Department of Oceanography, School of Ocean and Earth Science and Technology, University of Hawai'i at Mānoa, \\ Honolulu, Hawai'i 96822, USA \\ ${ }^{5}$ Department of Biology \& Aarhus Institute of Advanced Studies, Aarhus University, 8000 Aarhus C, Denmark \\ ${ }^{6}$ School of Life Sciences, University of Hawai'i at Mānoa, Honolulu, Hawai'i 96822, USA
}

\begin{abstract}
Many marine animals have a biphasic life cycle in which demersal adults spawn pelagic larvae with high dispersal potential. An understanding of the spatial and temporal patterns of larval dispersal is critical for describing connectivity and local retention. Existing tools in oceanography, genetics, and ecology can each reveal only part of the overall pattern of larval dispersal. We combined insights from a coupled physical-biological model, parentage analyses, and field surveys to span larval dispersal pathways, endpoints, and recruitment of the convict surgeonfish Acanthurus triostegus. Our primary study region was the windward coast of $\mathrm{O}^{\prime} \mathrm{ahu}$, Hawai'i. A high abundance of juvenile A. triostegus occurred along the windward coast, with the highest abundance inside Kāne'ohe Bay. The output from our numerical model showed that larval release location accounted for most of the variation in simulated settlement. Seasonal variation in settlement probability was apparent, and patterns observed in model simulations aligned with in situ observations of recruitment. The bay acted as a partial retention zone, with larvae that were released within or entering the bay having a much higher probability of settlement. Genetic parentage analyses aligned with larval transport modeling results, indicating self-recruitment of A. triostegus within the bay as well as recruitment into the bay from sites outside. We conclude that Kāne'ohe Bay retains reef fish larvae and promotes settlement based on concordant results from numerical models, parentage analyses, and field observations. Such interdisciplinary approaches provide details of larval dispersal and recruitment heretofore only partially revealed.
\end{abstract}

KEY WORDS: Larval dispersal · Self-recruitment · Coral reef · Coupled physical-biological modeling $\cdot$ Reef fish surveys $\cdot$ Parentage analysis $\cdot$ Connectivity $\cdot$ Acanthurus triostegus

\section{INTRODUCTION}

Many coastal fish species have complex life cycles wherein reef-associated adults produce pelagic larvae that are dispersed by oceanographic processes (Leis \& McCormick 2002) before returning to near- shore habitats (Paris \& Cowen 2004). For many coralreef fishes, larval dispersal is the predominant source of population connectivity between sites, given that juvenile and adult reef fish generally have restricted home ranges (Gaines et al. 2007, Green et al. 2015). For these species, distribution of adult populations

() The authors 2022. Open Access under Creative Commons by Attribution Licence. Use, distribution and reproduction are unrestricted. Authors and original publication must be credited.

Publisher: Inter-Research · www.int-res.com

\footnotetext{
*Corresponding author: counsell@hawaii.edu

\#Senior authors contributed equally and are listed alphabetically
} 
and connectivity between local populations are governed by the interplay of oceanographic dynamics, geographic features, larval behavior, and life history traits that influence patterns of larval dispersal (e.g. Hjort 1914, Caley et al. 1996, Schweigert et al. 2010, Peck et al. 2012). Depending on the species and environment, larval dispersal distances range anywhere from self-recruitment back to the same reef where spawned (Schultz \& Cowen 1994, Taylor \& Hellberg 2003, Jones et al. 2005, Cowen et al. 2006, Gerlach et al. 2007, Almany et al. 2017) to 100s of km (Kinlan \& Gaines 2003, Christie et al. 2010), with combinations of patterns also observed (Williamson et al. 2016, Johnson et al. 2018). Some of this variation in distance traveled is a result of temporal variability in the pelagic larval stage (Selkoe \& Toonen 2011), with pelagic larval duration (PLD) ranging from 7-94 d across reef fish species and intraspecific variability in PLD ranging from 3-56 d (Green et al. 2015). Thus, understanding spatial and temporal patterns in larval dispersal is key for understanding recruitment to local populations and subsequently informing spatial management strategies (Green et al. 2015). The complexity of relevant environmental and biological parameters, coupled with the small size of marine larvae, have historically obscured patterns in larval dispersal and population connectivity (Caley et al. 1996, Cowen et al. 2006, 2007, Botsford et al. 2009). Larval movement has long been regarded as one of the great 'black boxes' in marine ecology (Caley et al. 1996, Grosberg \& Levitan 1992), yet multidisciplinary approaches hold great promise for illuminating this enigmatic part of the marine life cycle (Petitgas et al. 2012, Williamson et al. 2016, Johnson et al. 2018, Hixon et al. 2022).

Oceanographic models can simulate virtual larvae through their pelagic journey and provide spatially and temporally extensive estimates of larval dispersal pathways and recruitment patterns (Cowen et al. 2006, North et al. 2009). Model simulations can explore a variety of conditions and depict the sensitivity of larval dispersal patterns to various oceanographic conditions. Critical to the success of predicting larval dispersal via oceanographic models is biological realism in the simulations of larval behavior combined with biologically appropriate scales for modeling water movement and physical attributes inclusive of near-shore regions (Metaxas \& Saunders 2009). Modeling larval dispersal provides predictions of how settlement patterns vary over time, including connectivity between sites and self-recruitment (Cowen \& Sponaugle 2009, Leis 2021). These predictions can be confirmed through ecological surveys of fish recruitment and genetic parentage analysis (Bode et al. 2019).

Genetic parentage analyses can be used to validate patterns of larval dispersal predicted by oceanographic models by directly identifying paired spawning and settlement locations (e.g. Planes et al. 2009, Christie et al. 2010, Almany et al. 2017). Genetic parentage analyses compare DNA between adults and new recruits, thereby connecting parent-offspring pairs (Christie et al. 2017, Coleman 2019). While single-nucleotide polymorphism (SNP)-based parentage analyses have become more accessible and cost-effective in recent years (Kraft et al. 2020), these analyses are still constrained by the need to collect tissue specimens from large numbers of individuals. This can make interannual variation hard to quantify, in part because of the extensive effort required to collect a large number of tissue samples, and in part because destructive sampling methods remove possible future adults from the population (however, see Catalano et al. 2021 for a 7 yr parentage study of an anemonefish). Further, post-settlement mortality, movement of recruits post-settlement, and movement of adults postspawning - all factors that can vary by location or season - can bias the population subset that is available to be sampled for parentage analysis.

Ecological surveys that provide in situ observations of juveniles can inform the relative distribution of fish recruits across reefs and regions. Since the planktonic larval phase is difficult to observe and track directly, visual surveys of small juvenile reef fish have been used to document presumed temporal and spatial variability in settlement patterns (e.g. Booth 1992, Doherty 2002, Fox et al. 2012). This approach can reveal the seasonality of recruitment events (Doherty 1991) as well as recruitment habitat characteristics (Randall 1961). Observed spatial and temporal variation in reef fish recruitment can be used to infer larval supply but can be confounded by post-settlement mortality and movement (Almany \& Webster 2006, Hixon et al. 2012). Despite these limitations, ecological investigations of life history strategies and behaviors are essential for documenting and predicting larval dispersal patterns (Pfeiffer-Herbert et al. 2007, North et al. 2008, McManus \& Woodson 2012, Faillettaz et al. 2018). The respective limitations and complementary strengths of oceanographic numerical models, ecological field surveys, and genetic parentage analyses are such that the integration of these approaches provides the best possible understanding of larval dispersal and population connectivity patterns (Petitgas et al. 2012, Williamson et al. 2016, Johnson et al. 2018, Hixon et al. 2022). 
Here, we combined methods and data from oceanography, genetics, and ecology to illuminate patterns of larval dispersal for an endemic Hawaiian reef fish, the convict surgeonfish Acanthurus triostegus sandvicensis. Locally known as manini, this species is an important food fish, selected for this study in consultation with Hawaiian fishers and cultural practitioners. We focused on the windward coast of $\mathrm{O}^{\prime} a h u$, Hawai'i, to examine the role of a large semi-enclosed embayment, Kāne'ohe Bay, for its potential as a source of larvae for the open coast, as a settlement location for larvae spawned outside the bay, and/or as a location of retention and selfrecruitment of larvae spawned within the bay. To evaluate the relative importance of biological and physical drivers on larval settlement of $A$. triostegus, we used a high-resolution oceanographic model of nearshore physical dynamics and the Connectivity Modeling System (CMS) as a Lagrangian particle dispersal model. We included known life history characteristics of A. triostegus in these models, enabling us to predict biologically realistic patterns of larval dispersal and settlement through space and time. To validate the connectivity projected by these simulations of virtual larvae, we incorporated parentage analyses of $A$. triostegus around O'ahu including focused efforts on the windward coast and within Kāne'ohe Bay (Coleman 2019). To assess the local distribution and dynamics of $A$. triostegus, we analyzed spatial patterns in size structure from diver surveys around $\mathrm{O}^{\prime} \mathrm{ahu}$. To identify temporal patterns in recruitment, we conducted periodic field surveys within Kāne'ohe Bay. By combining oceanographic, genetic, and ecological techniques, this study provides complementary insights into the spatial and temporal dynamics of larval dispersal and recruitment patterns.

\section{MATERIALS AND METHODS}

\subsection{Study site}

The island of O'ahu, Hawai'i, can be divided into 5 coastal regions based on prevailing weather patterns and currents (Fig. 1a). A central focus for our study, the windward eastern coast, is dominated by northeasterly trade winds (speeds typically 5-10 m $\mathrm{s}^{-1}$ ) nearly year-round (Fig. 1c). A dominant feature of the windward coast is Kāne'ohe Bay $\left(21.46^{\circ} \mathrm{N}\right.$, $157.81^{\circ} \mathrm{W}$ ), the largest sheltered body of water in the Hawaiian Islands (Lowe et al. 2009) at $52 \mathrm{~km}^{2}$ (along-shore length: $\sim 13 \mathrm{~km}$; cross-shore width:
4 km; Fig. 1d). Kāne'ohe Bay is bordered by a shallow (mean depth: $3-5 \mathrm{~m}$ ) fringing reef that extends over $12 \mathrm{~km}^{2}$. Beyond the fringing reef, the water depth drops sharply to $>20 \mathrm{~m}$. The sheltered part of Kāne'ohe Bay is 10-15 m depth with the exception of $>50$ coral patch reefs, which rise to within $<1 \mathrm{~m}$ of the surface. Water enters and exits Kāne'ohe Bay primarily through 2 main channels: a shipping channel (mean depth: $12 \mathrm{~m}$ ) in the north of the bay and a second small-craft channel (mean depth: $6 \mathrm{~m}$ ) in the south of the bay (Lowe et al. 2009). The southernmost region of Kāne'ohe Bay is a semi-enclosed area that functions as a bay within a bay (Fig. 1d).

\subsection{Study species}

Acanthurus triostegus is a common surgeonfish throughout the Indo-Pacific and the eastern tropical Pacific, adults of which are associated with hard substrate in lagoon and reef habitats (Randall 1961, 1986). The Hawaiian population was designated a distinct subspecies, A. t. sandvicensis, based on morphology and coloration (Randall 1956), a designation recently supported with genetic studies (Otwoma et al. 2018). While reproductive life history traits of $A$. triostegus can vary by location in the Hawaiian Islands, A. triostegus likely reaches sexual maturity in its first year. The average sizes of 1 and $2 \mathrm{yr}$ old individuals are 16 and $20 \mathrm{~cm}$ total length (TL), respectively (Longenecker \& Langston 2008), and a population on the southeast coast of O'ahu showed $50 \%$ of $13 \mathrm{~cm}$ TL individuals were sexually mature (Schemmel \& Friedlander 2017). The smallest sexually mature individual was $\sim 10 \mathrm{~cm}$ TL (Schemmel \& Friedlander 2017).

Spawning aggregations of 25-800 individuals have been observed in Hawai'i and follow a semilunar spawning periodicity, e.g. spawning within $4 \mathrm{~d}$ of new and full moons (Schemmel \& Friedlander 2017). Spawning effort varies across seasons and years, with windows of high spawning observed from December to August (Randall 1961, Schemmel \& Friedlander 2017). Resident spawning aggregations with home ranges of an estimated $<2 \mathrm{~km}$ of coastline (Robertson 1983) have been observed on the south shore of $\mathrm{O}^{\prime} \mathrm{ahu}$ at a depth of 7-10 $\mathrm{m}$ in an area with strong tidal flow (Schemmel \& Friedlander 2017). Spawning occurs during ebb tides between midday and dusk, with subgroups of the aggregation displaying synchronized rapid bursts of vertical swimming in which gametes are released within $1 \mathrm{~m}$ of the surface (Robertson 1983, Domeier \& Colin 1997). 


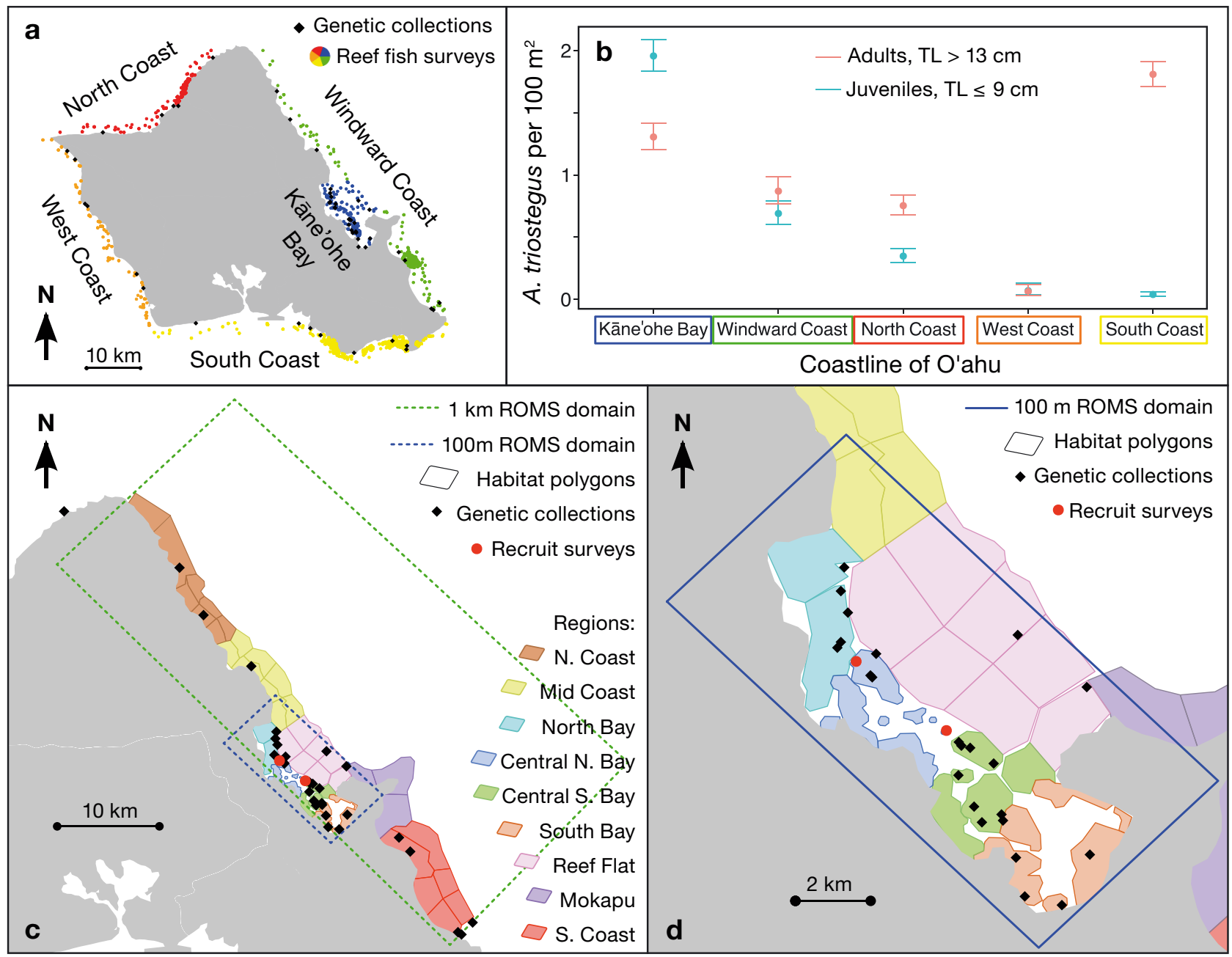

Fig. 1. (a) O'ahu, Hawai'i, divided into coastlines by colored dots for reef fish surveys accessed from a statewide database. Black diamonds: collection sites for genetic samples. (b) Acanthurus triostegus density by life stage and coastline, with colors on $x$-axis matching colors from (a). Points represent the mean density model estimate $\pm 95 \%$ CI for adult and juvenile fish. (c) Windward eastern coast of $\mathrm{O}^{\prime}$ ahu with the numerical model domains of nested Regional Ocean Modeling System (ROMS) overlaid (green and blue dashed lines). Habitat polygons $(n=53)$ are depicted and colored by habitat region $(n=9)$. Black diamonds: collection sites for genetic samples; red dots: 2 patch reefs in Kāne'ohe Bay at which recruit surveys were conducted. (d) Kāne'ohe Bay; black diamonds: collection sites for genetic samples; red dots: 2 patch reefs at which recruit surveys were conducted

Pelagic eggs hatch into pelagic larvae within $\sim 26 \mathrm{~h}$ (Randall 1956), with oriented swimming and feeding behaviors observed after $5 \mathrm{~d}$ (Longenecker \& Langston 2008). The PLD of A. triostegus ranges from 44-74 d, with post-larval stage juveniles arriving in intertidal habitats at a size of $2-3 \mathrm{~cm}$ TL (Randall 1961, McCormick 1999, Frédérich et al. 2012). As individuals grow, they migrate to slightly deeper lagoon, reef crest, and upper reef slope habitats (Sale 1968, Robertson 1983, Frédérich et al. 2012).

This ecological information on spawning time, spawning depth, PLD, and known habitat use for $A$. triostegus was used to parameterize our biophysical model.

\subsection{Oceanographic model}

\subsubsection{Regional Ocean Modeling System}

Ocean conditions were simulated for 2014 and 2015 using the Regional Ocean Modeling System (ROMS) with atmospheric forcing, tidal forcing, stream discharge, and bottom topography (Table 1, see Supplement at www.int-res.com/articles/suppl/m684p117_ supp.pdf). The model domain covered an area of $1404 \mathrm{~km}^{2}$ (Fig. 1c) along the windward coast of O'ahu. The ROMS for Kāne'ohe Bay had a 100 m resolution with 12 vertical layers (Fig. 1d), while the ROMS model for the windward coast had a $1 \mathrm{~km}$ resolution with 20 vertical layers. 
Table 1. Simulated reef fish larvae were modeled using a coupled physical-biological model. Model parameterizations are provided for the set of nested Regional Ocean Modeling Systems (ROMS; Shchepetkin \& McWilliams 2005) and a Connectivity Modeling System (CMS) that were used in model simulations of larval movement. SSH: sea surface height; SST: sea surface temperature

\begin{tabular}{|c|c|c|}
\hline Module & Parameter & Input \\
\hline \multirow{5}{*}{$\begin{array}{l}\text { ROMS, } \\
\text { Hawaiian Islands }\end{array}$} & Grid resolution & 4 km, Hawaiian Islands (Matthews et al. 2012) \\
\hline & Data availability & $3 \mathrm{~h}$ \\
\hline & Physical data & $\begin{array}{l}\text { Satellites (SSH, SST, and surface currents), Argo floats and gliders, high- } \\
\text { frequency radar }\end{array}$ \\
\hline & Atmospheric forcing & Weather Research and Forecasting Model (Michalakes et al. 2001) \\
\hline & Bottom topography & $\begin{array}{l}\text { Hawai'i Mapping Research Group of the Hawai'i Institute of Geophysics and } \\
\text { Planetology at the University of Hawai'i }\end{array}$ \\
\hline \multirow{5}{*}{$\begin{array}{l}\text { ROMS, } \\
\text { Windward Coast }\end{array}$} & Grid resolution & $1 \mathrm{~km}$, windward coast of $\mathrm{O}^{\prime} \mathrm{ahu}(54 \times 26 \mathrm{~km})$ \\
\hline & Vertical layers & 20 vertical layers of current velocities \\
\hline & Data availability & $1 \mathrm{~h}$ \\
\hline & Atmospheric forcing & Weather Research and Forecasting Model (Michalakes et al. 2001) \\
\hline & Bottom topography & $\begin{array}{l}\text { Hawai'i Mapping Research Group of the Hawai'i Institute of Geophysics and } \\
\text { Planetology at the University of Hawai'i }\end{array}$ \\
\hline \multirow{7}{*}{$\begin{array}{l}\text { ROMS, } \\
\text { Kāne'ohe Bay }\end{array}$} & Grid resolution & 0.1 km, Kāne‘ohe Bay $(14$ × 6.9 km) \\
\hline & Vertical layers & 12 vertical layers of current velocities \\
\hline & Data availability & $30 \min$ \\
\hline & Atmospheric forcing & $\begin{array}{l}\text { Weather Research and Forecasting Model, local configuration (Zhou \& Chen } \\
\text { 2014) }\end{array}$ \\
\hline & Tidal forcing & The OSU TOPEX/Poseidon Global Inverse Solution TPXO (Egbert et al. 1994) \\
\hline & Stream discharge & $\begin{array}{l}\text { Stream gauge data from the US Geological Survey were obtained from: } \\
\text { https://waterdata.usgs.gov/nwis/inventory/? site_no=ID, where ID is: } \\
16275000 \text { for He'eia; } 16294100 \text { for Waiāhole; } 16284200 \text { for Waihe'e; and } \\
16294900 \text { for Waikāne. }\end{array}$ \\
\hline & Bottom topography & $\begin{array}{l}\text { Blended data from the Pacific Islands Benthic Habitat Mapping Center } \\
\text { (https://www.soest.hawaii.edu/pibhmc/cms/) and the National Coastal } \\
\text { Mapping Program (2013 USACE NCMP Topobathy Lidar, } \\
\text { https://inport.nmfs.noaa.gov/inport/item/49755) }\end{array}$ \\
\hline \multirow[t]{11}{*}{ CMS } & Model boundary & ROMS Windward Coast and ROMS Kāne'ohe Bay \\
\hline & Land boundary & 'avoidcoast' model setting \\
\hline & Surface boundary & 'upperlevelsurface' model setting \\
\hline & Vertical layers & $\begin{array}{l}41 \text { fixed depth levels: } 0.5 \mathrm{~m} \text { intervals from } 0-10 \mathrm{~m}, 1 \mathrm{~m} \text { intervals from } \\
10-20 \mathrm{~m}, 5 \mathrm{~m} \text { intervals from } 20-30 \mathrm{~m}, 10 \mathrm{~m} \text { intervals from } 30-50 \mathrm{~m}, 25 \mathrm{~m} \\
\text { intervals from } 50-200 \mathrm{~m}\end{array}$ \\
\hline & Turbulence & $\begin{array}{l}\text { Horizontal dispersion coefficient of } 0.2 \mathrm{~m}^{2} \mathrm{~s}^{-1} \text { (Lowe et al. 2009) for ROMS } \\
\text { Kāne'ohe Bay and } 2 \mathrm{~m}^{2} \mathrm{~s}^{-1} \text { for ROMS Windward Coast } \\
\text { Vertical dispersion coefficient of } 0.001 \mathrm{~m}^{2} \mathrm{~s}^{-1} \text { (Durski et al. 2004) }\end{array}$ \\
\hline & Time step & $300 \mathrm{~s}$ \\
\hline & Release habitat sites & $\begin{array}{l}\text { Reef habitat polygons }(\mathrm{n}=53) \text { based on NOAA's National Centers for Coastal } \\
\text { Ocean Science benthic habitat maps }\end{array}$ \\
\hline & Release timing & $\begin{array}{l}\text { Egg release dates }(\mathrm{n}=32) \text { based on afternoon ebb tides in Hawai'i }(03: 00 \mathrm{~h} \\
\text { UTC, } 17: 00 \mathrm{~h} \text { HST }-1 \mathrm{~d}) \text { for new and full moons between Jan-Jul } 2014 \text { and } \\
\text { Dec } 2014-\text { July } 2015 \text { (Randall 1961, Schemmel \& Friedlander 2017) }\end{array}$ \\
\hline & Release depth & $\begin{array}{l}1.5 \mathrm{~m} \text { for sites } \leq 3 \mathrm{~m} \text { deep, } 3 \mathrm{~m} \text { for all other sites (Robertson 1983, Domeier \& } \\
\text { Colin 1997, Schemmel \& Friedlander 2017) }\end{array}$ \\
\hline & Release magnitude & 100 particles per each habitat site (5300 per release date) \\
\hline & Competence & $\begin{array}{l}\text { 55, 65, and } 75 \text { d pelagic larval durations (Randall 1961, Longenecker \& } \\
\text { Langston 2008) }\end{array}$ \\
\hline
\end{tabular}




\subsubsection{Connectivity Modeling System}

Particle motion was evaluated using CMS, a Lagrangian particle-tracking model that employs a $4^{\text {th }}$ order Runge-Kutta scheme to transport virtual larvae through a set of velocity fields with the ability to incorporate biological parameterization using an individual-based model (Paris et al. 2013). Larvae were set to be neutrally buoyant and passively advected throughout each model simulation (see Text S1). Pilot simulations were run in which larvae drifted for $65 \mathrm{~d}$ without any turbulent velocity to verify that the model was capturing expected regional oceanographic features. After this confirmation, the CMS turbulence module was used to provide randomness to larval trajectories and simulate motion on scales smaller than the grid resolution. Each virtual larva was perturbed in a random direction every $300 \mathrm{~s}$ at a velocity proportional to a specified dispersion constant (Table 1). To prevent larvae from becoming stranded on land, those that crossed shoreline boundaries were returned to their previous location and moved with reduced velocities or held in place to keep them in the water (avoidcoast model setting; Paris et al. 2013). When larvae crossed an open ocean boundary from the model domain (Fig. 1c), they were considered 'lost' from the simulation.

\subsubsection{Model simulations}

Areas of hard bottom habitat comparable to sites where juvenile and adult $A$. triostegus have been observed were defined using QGIS, based on the benthic habitat maps created by NOAA's National Centers for Coastal Ocean Science (Fig. 1c). The Seascape module within CMS was used to designate these habitat polygons $(n=53)$ as release and settlement locations for $A$. triostegus. To increase the interpretability of spatial patterns, these habitat polygons were grouped into 9 regions based on circulation patterns (Bathen 1968, Lowe et al. 2009; Fig. 1c,d). Following the observed semi-lunar spawning behavior of A. triostegus in Hawai'i, spawning events were simulated on afternoon ebb tides in Hawai'i (03:00 h UTC, 17:00 h HST - 1 d) for new and full moons from January to July 2014 and from December 2014 to July 2015. For each model simulation (32 release dates), 100 eggs were released at the centroid of each habitat polygon (53 release locations) at a depth of 1.5-3 m (Table 1). To test the effect of variation in PLD on the settlement success of $A$. triostegus, simulations were run for 3 PLDs: 55, 65, and $75 \mathrm{~d}$ (based on Randall 1961, Frédérich et al. 2012). Each model included a $10 \mathrm{~d}$ settlement window, such that after the designated PLD had elapsed, competent larvae that were not already within a habitat polygon had 10 additional days to enter a polygon. In total, 96 simulations were run with 5300 larvae in each model. For the 508800 virtual larvae released, 'successful settlement' refers to larvae that were within a habitat polygon at the end of the simulation.

\subsubsection{Settlement of virtual larvae}

To evaluate how much the biological components incorporated in model simulations accounted for variation in settlement, a set of generalized linear models (GLMs) were used (glm function in the stats package; R Core Team 2019). For each GLM, settlement was the binomial response variable, scored as 0 or 1 for larval absence or presence in habitat polygons at the end of the simulation. A set of single predictor models was used to directly consider the power of each predictor: PLD (Model 1), release date (Model 2; corresponds to spawning date, this variable was treated as a factor), window of release date (Model 3; the first window from January 2014 to July 2014 and the second window from December 2014 to July 2015), release habitat polygon (Model 4), and release habitat region (Model 5; included an offset for the number of polygons in a region). In addition to these GLMs focused on single predictor variables, a full model was fit with PLD, release date, window of release date, release habitat polygon, and release habitat region as predictors. This full model was used to investigate the effect of each predictor accounting for the variation of the other predictors and to work through a comprehensive model selection process (dredge function in the MuMIn package; Barton 2019) to identify the best-fit model (Model 6). To evaluate the significance of each predictor variable, a marginal likelihood ratio test was used (Anova function in the car package; Fox \& Weisberg 2019). Akaike's information criterion (AIC) scores were used to compare model fit across all GLMs. Residuals from each model were confirmed to follow the expected distribution visually using $\mathrm{QQ}$ plots and plots of residuals against fitted values.

To evaluate spatial patterns in settlement, the observed distribution of settlers across habitat polygons was compared to a random distribution (scaled to the surface area of each habitat polygon) of settlement across habitat polygons using a Pearson's $\chi^{2}$ test (chisq.test function from the stats package; R Core 
Team 2019). This analysis was repeated at the regional scale. To visualize population connectivity between habitat polygons and regions, connectivity matrices were created using larval release and settlement location data from the oceanographic models.

\subsection{Parentage analyses for A. triostegus}

To evaluate the population connectivity patterns predicted through simulations, we incorporated data from parentage analyses conducted on A. triostegus around O'ahu (see Coleman 2019 for details). To briefly summarize, a genetic parentage analysis based on 399 SNPs was conducted from 1213 A. triostegus samples (606 adults, 607 juveniles) collected across 23 sites around O'ahu (Fig. 1a). The sampling effort was focused on the windward coast (Fig. 1c) and included collections from multiple patch reefs within Kāne'ohe Bay (Fig. 1d). Parent-offspring assignments were determined using CERVUS v.3.0.7 (Marshall et al. 1998, Kalinowski et al. 2007). CERVUS calculates the likelihood that each candidate is the parent, taking into account population allele frequencies and genotype errors. Parent-offspring assignments were accepted at a $95 \%$ confidence level resulting in 68 assignments (11\% assignment rate) with a $2 \%$ average chance of being a false assignment. Using the collection sites of adult and juvenile samples from each genetically linked pair, genetically confirmed examples of population connectivity were linked to spawning (parent) and settlement (offspring) habitat polygons (Fig. 1c).

\subsection{Spatial and temporal patterns of A. triostegus populations}

To evaluate spatial patterns in the population size structure of $A$. triostegus around $\mathrm{O}^{\prime} \mathrm{ahu}$, we accessed reef fish survey data from a statewide database. We used data from 1949 reef fish surveys of hard bottom sites conducted by 5 research organizations (i.e. Coral Reef Assessment and Monitoring Program of the University of Hawai'i, NOAA, State of Hawai'i Division of Aquatic Resources, Fisheries Ecology Research Lab of the University of Hawai'i, and The Nature Conservancy) from 2000-2016. Counts of A. triostegus were standardized to number per $100 \mathrm{~m}^{2}$ to account for differences in the survey methods. Observed A. triostegus were categorized as either juveniles $(\leq 9 \mathrm{~cm})$ or adults $(>13 \mathrm{~cm})$. Using a GLM, we analyzed the effect of life stage (LifeStage: juve- nile or adult) and the 5 coastal regions of O'ahu (Region) on the density of A. triostegus (Density) as:

$$
\begin{gathered}
\text { Density Region + LifeStage } \\
+ \text { Region:LifeStage + Depth }
\end{gathered}
$$

The model included the main effects of Region and LifeStage as well as an interaction between Region and LifeStage. Reef depth (Depth) was included in the model as a predictive factor to account for variation across survey sites. The model was fit using a negative binomial distribution to account for over-dispersion (glm.nb function in the Mass package; Venables \& Ripley 2002). Residuals from each model were confirmed to follow the expected distribution visually using $\mathrm{QQ}$ plots and plots of residuals against fitted values. A marginal likelihood ratio test was used to evaluate the significance of Region, LifeStage, and the interaction term (Anova function in the car package; Fox \& Weisberg 2019).

To measure temporal variability in A. triostegus recruitment and to estimate the synchrony of recruitment inside Kāne'ohe Bay, we conducted monthly surveys of $A$. triostegus at 2 representative patch reefs (each reef approximately $45 \mathrm{~m}$ in diameter) within Kāne'ohe Bay from March 2015 to March 2016. Surveys were increased to a frequency of twice a month from May 2015 through September 2015 for a total of 18 survey dates. Both patch reefs were in the Central North Bay region of Kāne'ohe Bay (reefs marked by red dots in Fig. 1d), with one at the northern boundary $\left(21.4753^{\circ} \mathrm{N}, 157.8300^{\circ} \mathrm{W}\right)$ and the other at the southern boundary $\left(21.4576^{\circ} \mathrm{N}, 157.8069^{\circ} \mathrm{W}\right)$. On each patch reef, ten $25 \mathrm{~m}$ transects were surveyed: 4 on the reef slope (depth: $4.5 \mathrm{~m}$ ), 4 on the reef crest $(2.1 \mathrm{~m})$, and 2 on the reef top $(\leq 1 \mathrm{~m})$. On the outbound swim of each transect, fish $>5 \mathrm{~cm}$ TL were surveyed within a $4 \mathrm{~m}$ belt; on the return swim, fish $\leq 5 \mathrm{~cm}$ TL were surveyed within a $2 \mathrm{~m}$ belt. To improve our estimates of the age of recruits, the TL of A. triostegus was visually estimated to $0.5 \mathrm{~cm}$ for fish $<10 \mathrm{~cm}$ TL. At the start of each survey, teams spent 10-30 min estimating the size of model fish to recalibrate their underwater visual size estimation with an emphasis on fish $<10 \mathrm{~cm}$ TL.

We used a zero-inflated Poisson model (glmmTMB function in the glmmTMB package; Brooks et al. preprint doi:10.1101/132753) to determine whether the number of juveniles $(\leq 9 \mathrm{~cm}$; Juveniles), when observed, differed between the northern and southern patch reef (Site) or across survey month (Month):

$$
\text { Juveniles } \sim \text { Site }+ \text { Month }+(1 \mid \text { ReefDepth })
$$


The model includes main effects of Site and Month. Reef depth (ReefDepth) was included as a random effect given that juvenile $A$. triostegus use shallow reef tops more than other regions of patch reefs. Date of spawning was estimated for all observed juveniles ( $\leq 9 \mathrm{~cm}$ TL) as: date observation $_{-}$age $_{\text {days. }}$ The age in days since spawning was calculated by inputting the observed size of each individual into the growth equation for $A$. triostegus (Longenecker \& Langston 2008). A zero-inflated Poisson model was used because $A$. triostegus juveniles were not present for $>75 \%$ of surveys, and yet, when $A$. triostegus juveniles were present, observations ranged from 1-27 juveniles transect ${ }^{-1}$. For this 2-stage model, residuals were simulated ('simulateResiduals' function in the DHARMa package; Hartig 2021) and then visually inspected using a QQ plot. No deviations from the expected distribution were observed.

We conducted our statistical analyses in R v.3.6.1 ( $R$ Core Team 2019).

\section{RESULTS}

\subsection{Modeled predictions of settlement}

Of all 508800 simulated larvae, one-third (33\%) settled within the study area. Given the large number of virtual larvae modeled, all predictive factors included in GLMs for the probability of settlement were statistically significant (ANOVA, $\mathrm{p}<0.0001$ ). The best fit model included release polygon, release date, and PLD (Model 6, $\mathrm{r}^{2}=0.44$; Table 2); however, models that included only spatial factors, i.e. release region (Model 5, $\mathrm{r}^{2}=0.43$ ) described nearly the same amount of variation. Interactions between larval release polygon, release date, and PLD may explain why release date and PLD were retained in the best fit model despite small contributions to the explained variation.

Settlement differed by release polygon (Model 4; Fig. 2a) with clear regional patterns (Model 5). South Bay had the greatest probability of settlement (91\%), followed by Central South Bay (75\%), North Bay (72\%), Central North Bay (51\%), and Reef Flat (27\%). Larvae released in regions outside of Kāne'ohe Bay had lower probabilities of settlement than larvae released in regions inside the bay: North Coast (2\%), Mid Coast (6\%), Mokapu (11\%), and South Coast $(1 \%)$. These patterns of settlement across habitat polygons and regions were non-random $\left(\chi^{2}\right.$ test, $\mathrm{p}<0.0001$; Fig. 2b).

Release date accounted for $<1 \%$ of variation (Model 2; Table 2) in settlement. In both years of study, the highest probabilities of settlement were observed in late March and early April (maximum mean estimate was $43.4 \%$ for 18 April 2015 release date), and the lowest probabilities of settlement were observed in January and early February (minimum mean estimate was $22.3 \%$ for 16 January 2014 release date; Fig. 3). The probability of settlement was higher for larvae released in 2015 (33.5\%) than in 2014 (32.1\%) (Model 3; Fig. 3), but the difference between 2014 and 2015 release dates (Model 3; Table 2) accounted for $<0.1 \%$ of variation in settlement. The probability of settlement was higher for larvae with shorter PLDs, ranging from $31.2 \%$ for a $75 \mathrm{~d}$ PLD to $34.7 \%$ for a 55 d PLD (Model 1; Table 2, Fig. 3), but PLD accounted for $<0.1 \%$ of variation in settlement (Model 1; Table 2).
Table 2. GLM output for a set of models with binomial distribution for the probability of settlement as a binary response (pS) for simulated reef fish larvae. The first 5 models are single predictor models for pelagic larval duration (PLD), the date of simulated larvae release (a discrete factor), the time window of the simulated larvae release (a 2-level factor representing each of the $2 \mathrm{yr}$ of study), the specific habitat polygon of simulated larvae release, and a broader metric for the region of simulated larvae release. The final model (6) is the best fit model from a comprehensive model selection process run on a full model with all 5 predictor variables included. $\mathrm{R}^{2}$ values are calculated as 1 - (residual deviance / null deviance)

\begin{tabular}{|lccc|}
\hline Model & AIC & UAIC & $\mathrm{R}^{2}$ \\
\hline (1) $\mathrm{pS} \sim$ PLD & 643907 & 285792 & 0.0007 \\
(2) $\mathrm{pS} \sim$ release date & 638162 & 280047 & 0.0097 \\
(3) $\mathrm{pS} \sim$ release time window & 644269 & 286154 & 0.0002 \\
(4) $\mathrm{pS} \sim$ release habitat polygon & 370896 & 12781 & 0.4246 \\
(5) $\mathrm{pS} \sim$ release region + offset(N polys) & 386678 & 28563 & 0.4259 \\
(6) $\mathrm{pS} \sim$ PLD + release date + release habitat poly & 358115 & 0 & 0.4445 \\
\hline
\end{tabular}

\subsection{Modeled dispersal}

A portion of virtual larvae released from every habitat polygon dispersed to outside the model domain. This was the prevailing route for larvae released from the North Coast, Mid Coast, Mokapu, and South Coast, but also included larvae released within Kāne'ohe Bay (Fig. 4). Among larvae that were retained within the model domain, the strongest connectivity signals were for sites within Kāne'ohe Bay (Fig. 4). Larvae released from habitat polygons in the Central North Bay, Central South Bay, and South Bay often 

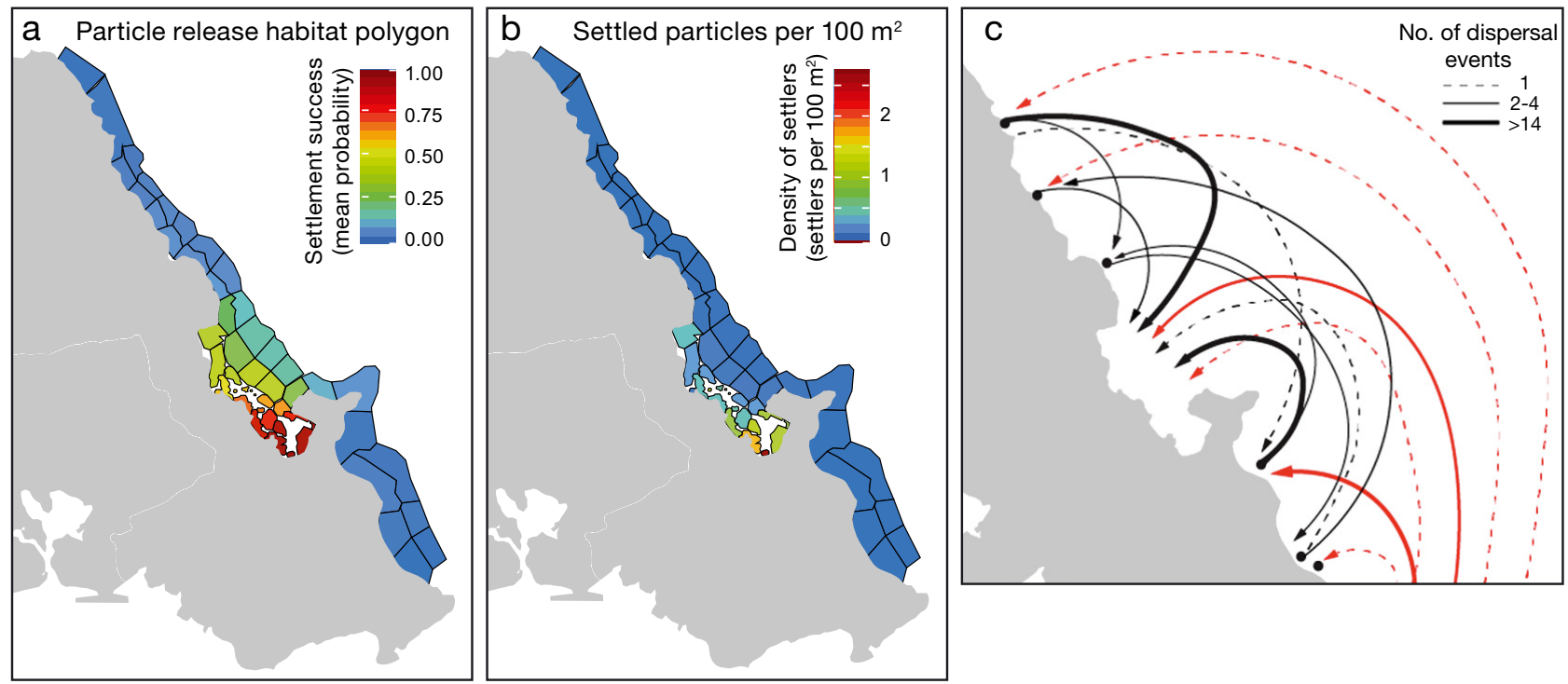

Fig. 2. (a) Simulated reef fish larval settlement by release polygon along the windward coast of O'ahu, in which the color corresponds to the proportion of all particles released at that habitat polygon that were in any of the habitat polygons at the end of the model simulation. (b) Spatial distribution of settlement across habitat polygons in which the color corresponds to the number of particles that settled in that habitat polygon scaled to the area of the habitat polygon. (c) Parentage analysis for Acanthurus triostegus on the windward coast of $\mathrm{O}^{\prime} \mathrm{ahu}$. Arrows: directionality of dispersal; red lines: juveniles spawned outside of the windward coast; black lines: juveniles spawned along the windward coast. Line thickness is proportional to the number of recruits connecting the location of origin to final settlement location. Redrawn from Coleman (2019)

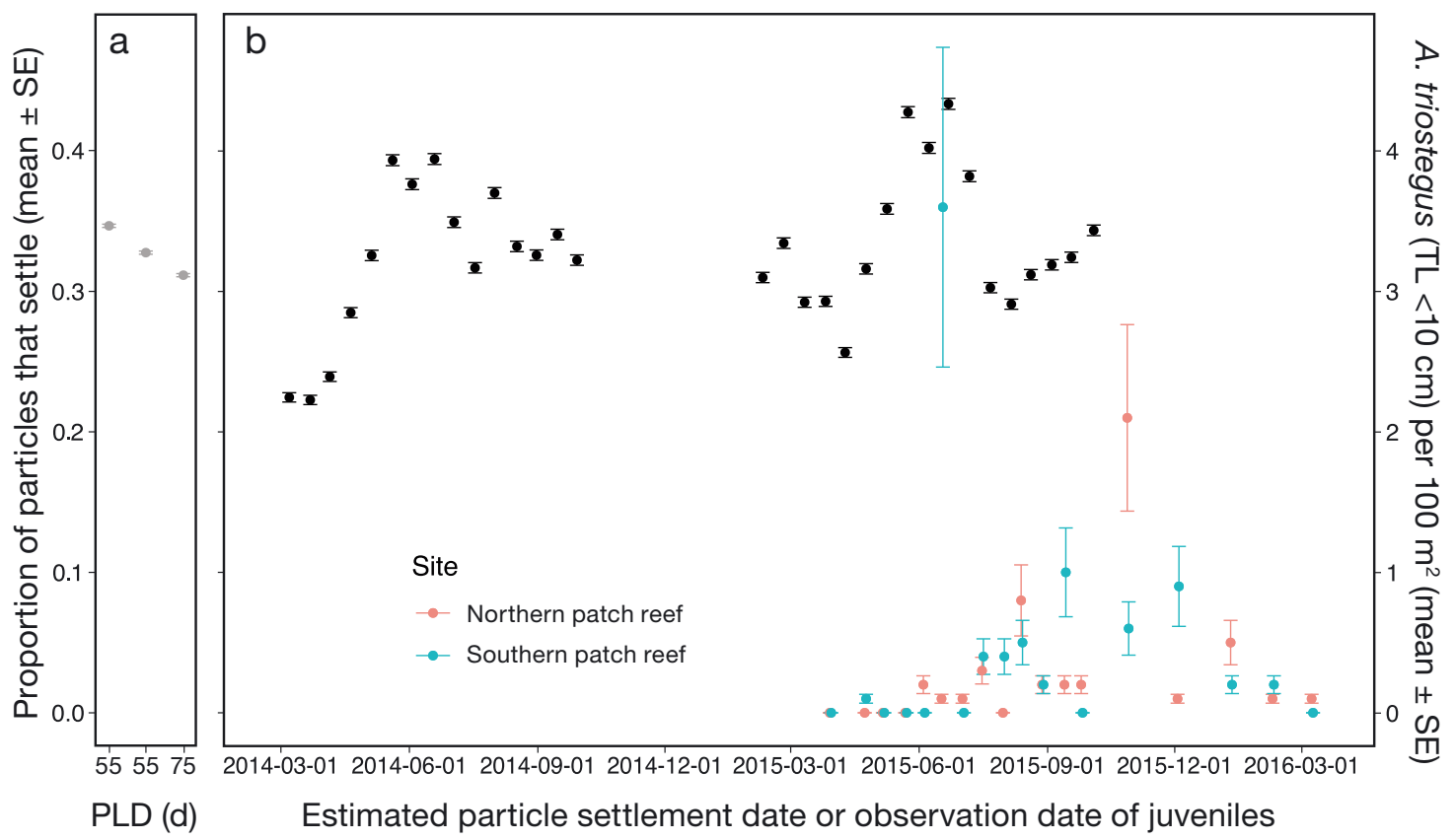

Fig. 3. Proportion (mean \pm SE) of simulated larvae that settled in the study area based on a particle tracking model for Acanthurus triostegus by (a) pelagic larval duration (PLD; gray points) and (b) release date (black points). Given the large number of modeled particles, SE bars cannot easily be seen. Release date was converted to an estimated particle settlement date (release date $+65 d$, which is the middle point of PLDs used across all model runs). Overlaid on (b) is the in situ recruit survey data (colored points) as the mean $( \pm \mathrm{SE})$ number of juveniles per transect by patch reef and survey date $(18$ survey dates, 2 patch reefs, $\mathrm{n}=10$ transects each). The time periods for field observations and model runs have incomplete overlap. Recruit survey data was collected from March 2015 to March 2016; particle tracking model runs included release dates from January 2014 to July 2015 corresponding to estimated particle settlement dates from March 2014 to October 2015 


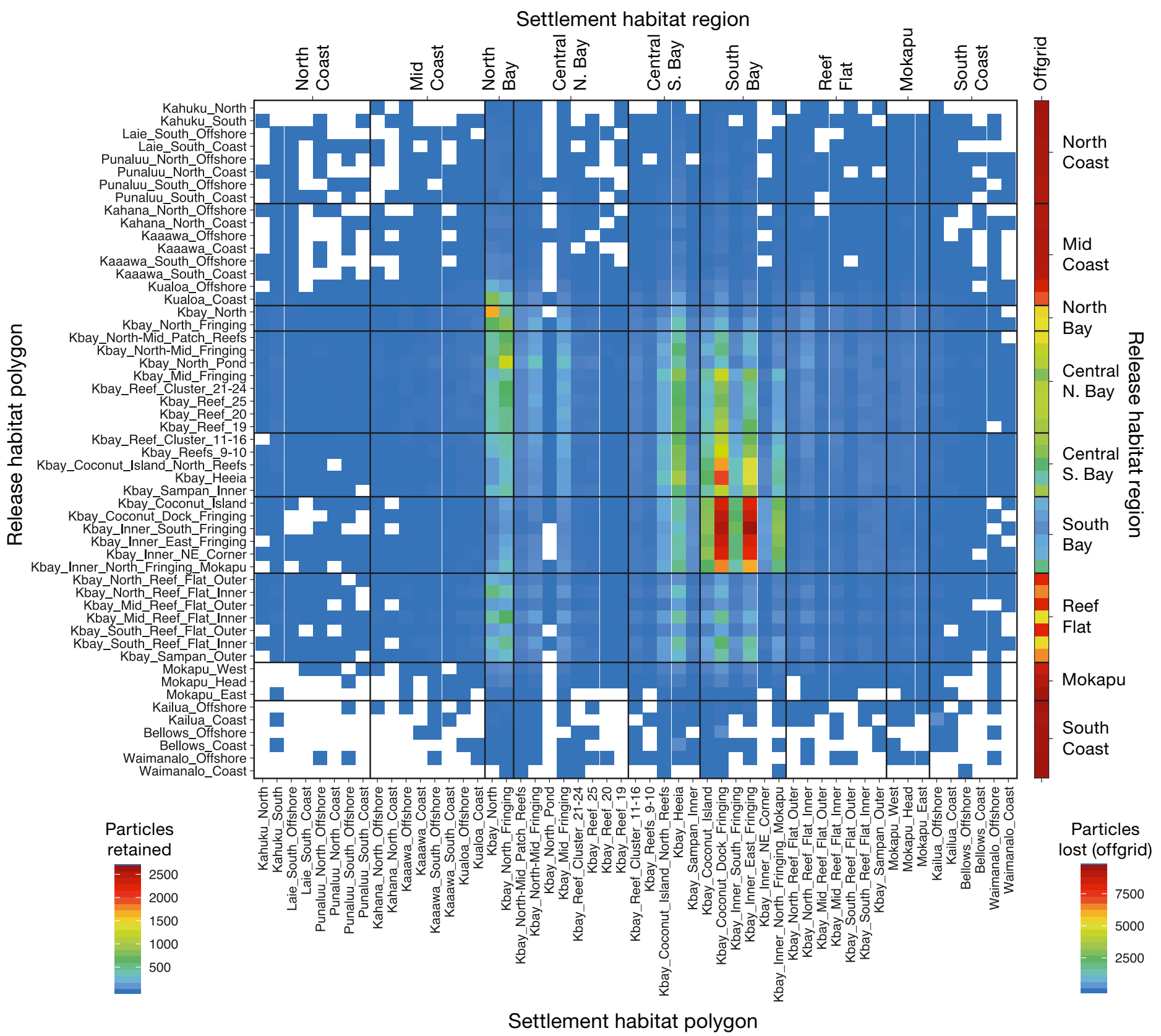

Fig. 4. Connectivity matrix for oceanographic model simulations of reef fish larval dispersal along the windward coast of O'ahu. Color scale for the matrix ranges from 0-2500 particles connecting polygons, with blue for low numbers of particles and red for high numbers of particles. White boxes reflect polygon pairs that did not have any connecting particles. A separate color scale is used to depict particles that moved offgrid and were lost from the model (ranges from 0 to over 8000 particles)

settled within the South Bay or Central South Bay. Larvae released in the North Bay, Central North Bay, and Central South Bay often settled within the North Bay. Larvae released on the Reef Flat along the outside of Kāne'ohe Bay often dispersed to habitat polygons in Kāne'ohe Bay (North Bay, Central South Bay, and South Bay; Fig. 4). Further, larvae released at habitat polygons along the north and south coastal edges of Kāne'ohe Bay had connectivity to sites within the bay. Larval dispersal patterns from model simulations included self-recruitment, in which virtual larvae settled in the same habitat polygon from which they were released, for 45 of 53 habitat polygons $(85 \%$; Fig. 4). Self-recruitment was strongest within Kāne'ohe Bay, particularly within the North Bay and South Bay regions (Fig. 4). 


\subsection{Parentage analyses}

From 1213 Acanthurus triostegus samples (606 adults, 607 juveniles) collected around O'ahu, 67 parent-offspring assignments were confirmed to have been spawned or settled along the windward coast. Genetic evidence confirmed the dispersal of larvae from the windward coast to areas outside of the windward coast. For 3 adult-juvenile pairs, adults on the windward coast ( 1 from Mid Coast and 2 from South Coast) were connected to juveniles outside of the windward coast (Figs. 2c \& 5). This connectivity pathway ran in both directions. Eight windward coast juveniles (2 on the North Coast, 3 on the South Coast, and 3 within the Central South Bay) were confirmed offspring of adults sampled outside of the windward coast.

Movement of offspring into Kāne'ohe Bay was the strongest connectivity pathway identified with

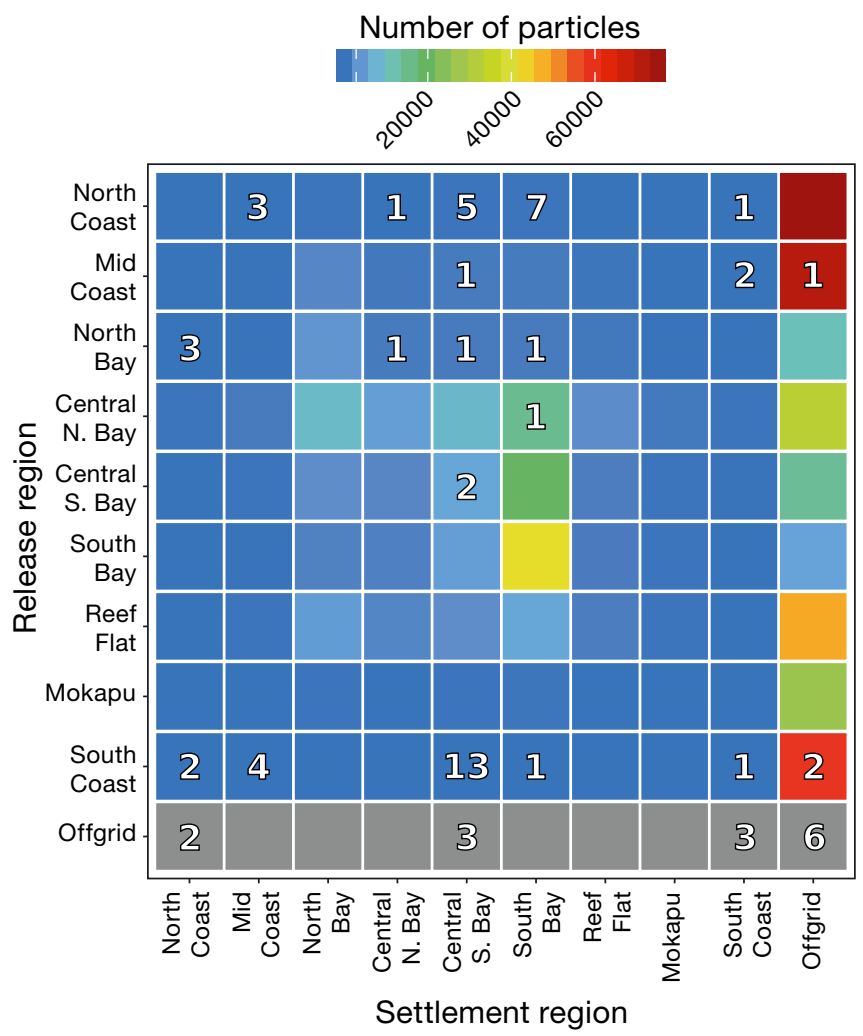

Fig. 5. Connectivity matrix for oceanographic model simulations of reef fish larval dispersal along the windward coast of O'ahu with data aggregated to the region scale. Confirmed numbers of juvenile-adult pairs between regions based on parentage analyses are overlaid (white numerals). The location of each adult is used for the release region, and the location of the juvenile is used for the settlement region. Sampling effort for the parentage analyses was not evenly divided among regions, with intensified efforts in Central S. Bay, which was the most easily accessed parentage analyses (42\% of parent-offspring assignments). In total, 28 juveniles found within Kāne'ohe Bay (Central North Bay, Central South Bay, and South Bay) originated from adults found on the windward coast (North Coast, Mid Coast, and South Coast; Figs. 2c \& 5). In addition to windward sites feeding into Kāne'ohe Bay, there were 3 examples of adults that were in Kāne'ohe Bay sending larvae to sites outside the bay (from the North Bay to the North Coast; Figs. 2c \& 5).

Parentage analyses were consistent with model predictions of larval retention within Kāne'ohe Bay. Six juveniles within Kāne'ohe Bay (Central North Bay, Central South Bay, and South Bay) were connected to adults found within Kāne'ohe Bay (North Bay, Central North Bay, and Central South Bay; Figs. 2c \& 5). Selfrecruitment of $A$. triostegus was confirmed for 2 habitat regions: the South Coast (1 parent-offspring pair found on the Kailua Coast) and the Central South Bay (2 parent-offspring pairs found in the Kāne'ohe Bay Reef Cluster 11-16).

\subsection{In situ patterns of $\boldsymbol{A}$. triostegus distribution and abundance}

The relative abundance of $A$. triostegus differed among coastal regions of $\mathrm{O}^{\prime} \mathrm{ahu}(\mathrm{p}<0.001)$ and across depth (ranging from $0.3-29 \mathrm{~m}$ ), with more $A$. triostegus at shallower depths $(\mathrm{p}<0.001)$. More adults than juveniles were observed overall ( $p<0.001)$, yet juveniles and adults followed distinct spatial patterns $(\mathrm{p}<$ 0.001). In Kāne'ohe Bay, abundance of juveniles was higher than adults (2.0 juveniles versus 1.3 adults per $100 \mathrm{~m}^{2}$; Fig. 1b). In contrast, the south coast had the highest abundance of adults and the lowest abundance of juveniles (1.8 adults versus 0.04 juveniles per $100 \mathrm{~m}^{2}$; Fig. 1b).

In surveys at 2 patch reefs within Kāne'ohe Bay, we observed 131 juvenile A. triostegus over 18 survey dates from March 2015 to March 2016. When juveniles were observed, the number of juveniles was different between the northern and southern patch reef ( $\mathrm{p}<0.001$ ) and across survey months ( $\mathrm{p}<0.0001)$. Overall, more juveniles were observed on the southern patch reef than the northern patch reef (Fig. 3). Juveniles were more likely to be observed from June through October than during the rest of the year (Fig. 3). Dates of spawning estimated from the observed sizes of juvenile $A$. triostegus ranged from January 2015 to November 2015. Estimated spawning dates indicate a successful spawning event between January and March 2015 that resulted in 
higher settlement on the southern patch reef $(n=36)$ than on the northern patch reef $(n=2)$ in June. There was evidence of a few smaller successful spawning events in May and June 2015 (Fig. 3).

\section{DISCUSSION}

Oceanographic, genetic, and ecological lines of evidence all indicate that Kāne'ohe Bay serves as an effective retention zone for Acanthurus triostegus larvae spawned along the windward coast of O'ahu. In the biophysical model, larvae released within Kāne'ohe Bay had a much higher chance of settlement than larvae released in other windward coast regions (Fig. 2a), and larval settlement was higher to sites within Kāne'ohe Bay (Fig. 2b). In the parentage analysis, more than half of the genetically linked adult-juvenile pairs showed self-recruitment within the bay (Fig. 5). In situ survey data confirmed the highest abundance of juvenile $A$. triostegus within Kāne'ohe Bay compared to other coastal regions of O'ahu (Fig. 1b). Evidence from these complementary approaches aligns with expectations from coastal dynamics: larval retention along the windward coast of O'ahu is expected to be strengthened by the trade winds in this region, which move in an on-shore direction with an average annual wind speed around $6 \mathrm{~m} \mathrm{~s}^{-1}$. Higher retention of larvae within Kāne'ohe Bay aligns with high particle retention times (Lowe et al. 2009). The semi-enclosed nature of Kāne'ohe Bay shelters larvae from along-shore and offshore water movement.

Oceanographic and genetic evidence similarly connect regions within Kāne'ohe Bay to regions outside of the bay. Biophysical model simulations indicated that adults along the windward coast are a source for juveniles within Kāne'ohe Bay (Fig. 4); this pattern was confirmed through multiple adult-juvenile pairs in the genetic data (Fig. 2c). While our results predominately support the importance of Kāne'ohe Bay for retaining A. triostegus recruits, our model simulations predicted, and our genetic data confirmed, that adults within Kāne'ohe Bay can be a source, albeit a relatively weak one, of juveniles for sites outside of the bay (Figs. 4 \& 5).

Spatial variation in larval retention and connectivity was apparent within the bay. Simulations of virtual larvae showed and parentage analyses validated connectivity among sites within Kāne'ohe Bay (Fig. 4), including support for self-recruitment at specific regions within the bay. Patterns of larval dispersal between sites within Kāne'ohe Bay primarily fol- lowed a north-to-south gradient. Virtual larvae released in northern regions of the bay regularly settled in southern regions of the bay, and parentage analyses validated north-to-south dispersal patterns within Kāne'ohe Bay. In addition to the support for a north-to-south dispersal pattern, in situ survey data and particle tracking models both indicated an overall pattern of higher recruitment in the southern region of Kāne'ohe Bay. The southeastern part of the bay has high particle retention times (1-2 mo) and limited water exchange both with other parts of Kāne'ohe Bay and with the coastal ocean (Lowe et al. 2009); hence, high water retention may be a driving factor for high larval retention in the southern part of Kāne'ohe Bay.

Larval dispersal simulations and parentage analyses provided evidence for connectivity along the windward coast and to other coastal regions of O'ahu. Some simulated larvae connected between windward coast sites, and $19 \%$ of genetically confirmed adultjuvenile pairs connected adults with juveniles between sites on the windward coasts. Simulations showed that some larvae were dispersed to outside of the windward coast model domain, and this dispersal to outside of the windward coast was greatest for larvae released from sites outside of Kāne'ohe Bay. Parentage analyses validated along-shore larval movement away from the windward coast through connections between adults on the windward coast and larvae settled elsewhere on O'ahu. Onshore winds and along-shore currents, including the North Hawaiian Ridge Current, simultaneously act as a barrier to offshore dispersal (Basterretxea et al. 2013) and contribute to the movement of larvae across coastlines.

In addition to the spatial concordances between our oceanographic, genetic, and ecological data, there were temporal alignments as well. Our results indicate that physical dispersal dynamics did not drive large differences in annual recruitment success of reef fishes between 2014 and 2015, though they do help to account for seasonal settlement patterns. Simulations indicated that settlement success occurs across a wide variety of release dates and corresponding oceanographic conditions. In situ observations of juveniles in Kāne'ohe Bay confirmed that some settlement occurred throughout the year. Seasonally, the highest probability of settlement was for virtual larvae released in March and April. While our ecological surveys did not have complete temporal overlap with our oceanographic model simulations, in situ observations of juveniles in Kāne'ohe Bay confirmed a peak in settlement from June to November (Fig. 3). 
Despite advances in oceanographic models and the alignment of our simulations with in situ survey data and parentage analyses, there are still limitations to simulating larval dispersal. For example, our model predictions should not be used to estimate actual numbers of settled reef fish. We released 100 eggs per location and date, while in the natural environment an estimated 22000 to 362000 pelagic eggs are released per female per spawning event (Longenecker \& Langston 2008). Further, our model does not include larval mortality, likely leading to an overestimation of proportional settlement success given the extremely high mortality of marine larvae in the natural environment (Garrido et al. 2015). In contrast, larvae that crossed grid boundaries were lost from the model, corresponding to an underestimation of total successful recruitment. Another model limitation was the exclusion of complex larval reef fish behaviors, such as orientation to light polarization axes (Mouritsen et al. 2013, Berenshtein et al. 2014), swimming towards chemical cues of habitat quality (Gerlach et al. 2007, Dixson et al. 2008, 2014, Lecchini et al. 2013, Paris et al. 2013, Coppock et al. 2020), and swimming towards reef sounds (Simpson et al. 2008, Vermeij et al. 2010). Ontogenetic vertical migration was included in preliminary simulations (Text S1), but many of the larvae became stranded in the shallow areas of Kāne'ohe Bay, negating the value of including this behavior in our model. We examined varying PLDs and found that although PLD accounted for $<0.1 \%$ of the variation in settlement, shorter PLDs resulted in slightly higher settlement success for $A$. triostegus, aligning with a previous study of PLDs (Sanvicente-Añorve et al. 2018). Intraspecific variation in PLD may be the result of variability in food availability (Dower et al. 2009) or water temperatures (Dekshenieks et al. 1993, McLeod et al. 2013). As particle tracking models continue to advance in their computing capacity and our knowledge of larval behavior increases (Swearer et al. 2019), simulating more nuanced larval behaviors will continue to strengthen the predictive power of biophysical models and narrow the spatial and temporal alignment with ecological and genetic observations.

Understanding larval dispersal patterns is critical to examining geographic aspects of marine population dynamics (Satterthwaite et al. 2021), as larval dispersal is the main connection between locations for many marine species. Unfortunately, understanding population connectivity via larval dispersal has presented a major challenge for marine ecology given the vast potential range of movement and the small size of larvae (Cowen et al. 2006, 2007, Botsford et al. 2009). In this study, we explored the power of combining oceanographic model simulations with in situ ecological survey data and genetic parentage analyses to reveal patterns in settlement success and intergenerational connectivity for a reef fish. Our results highlight spatial patterns and the importance of a large embayment for retaining $A$. triostegus recruits both from adults found within the bay and from adults along the broader windward coast of $\mathrm{O}^{\prime} \mathrm{ahu}$. High settlement success and self-recruitment were observed in the bay, particularly in the semi-enclosed southern part of the bay.

Using a multidisciplinary approach, we demonstrated that a large tropical embayment acted as a population sink and a favorable juvenile growth location for a coral reef fish, and suggest that this conclusion likely applies to many reef fishes with similar life histories. The concordance among 3 disparate approaches reinforces our conclusions and provides greater confidence in finding biologically realistic answers through oceanographic models that incorporate relevant life history. Understanding larval dispersal and the subsequent connectivity among sites is fundamentally important for guiding effective management strategies, including marine protected areas (Pelc et al. 2010) and recovery plans (Gouezo et al. 2021). Broader application of these multipronged methods would enhance fisheries management and the placement of marine protected areas for coral reef fishes.

Acknowledgements. This interdisciplinary work was supported by research labs at the University of Hawai'i led by B.W.B., M.J.D., E.C.F., M.A.H., S. A. Karl, M.A.M., B.S.P., and R.J.T. Additional project support came from E. Firing, C. Jerolmon, E. Schemmel, L. Teneva, L. Veazey, P. Moehlenkamp, and G. Walker. Boat and dive safety guidance came from J. Jones. Contributions to fieldwork were from K. Bahr, E. Barba, G. Burgess, D. Coffey, M. Hoban, G. Holns, C. Jerolmon, M. Kapur, D. Kraft, S. Leitner, C. Lescher, J. Levy, S. Mahaffey, E. Nalley, J. Paillusseau, J. Patterson, M. Russell, S. Tucker, G. Walker, L. Weaver, R. Weible, T. Wester, M. Winston, and J. Zill. Primary funding was provided by the Castle Foundation (Grant No. 3846, M. Hixon PI), University of Hawaii Sea Grant College Program (Grant No. NA14OAR4170071, B.W.B. and S. A. Karl PI), and the Office of Naval Research (Award No. N00014-17-1-2206 Subtask 6.2: Ocean Modeling, M.A.M.). C.W.W.C.'s participation in this study was supported by a National Science Foundation Graduate Research Fellowship (Grant No. 2012103208). R.R.C.'s participation was supported by the NOAA Office of National Marine Sanctuaries, Dr. Nancy Foster Scholarship (Award No. NA15NOS4290067). S.S.L.'s participation was supported by an East-West Center Scholarship. E.C.F.'s participation was supported by NOAA Fisheries award NA15NMF4520361. This is the University of Hawai'i at Mānoa SOEST contribution 11470, HIMB contribution 1875, Hawai'i SeaGrant contribution JC-16-37, and School of Life Sciences contribution 164. 


\section{LITERATURE CITED}

Almany GR, Webster MS (2006) The predation gauntlet: early post-settlement mortality in coral reef fishes. Coral Reefs 25:19-22

Almany GR, Planes S, Thorrold SR, Berumen ML and others (2017) Larval fish dispersal in a coral-reef seascape. Nat Ecol Evol 1:0148

* Bartoń K (2019) MuMIn: multi-model inference. R package version 1.43.6. https://CRAN.R-project.org/package= MuMIn

* Basterretxea G, Catalán IA, Jordi A, Alvarez I, Palmer M, Sabatés A (2013) Dynamic regulation of larval fish selfrecruitment in a marine protected area. Fish Oceanogr 22:477-495

Bathen KH (1968) A descriptive study of the physical oceanography of Kaneohe Bay, Oahu, Hawaii. Report no. 14. Hawaii Institute of Marine Biology, Honolulu, HI

Berenshtein I, Kiflawi M, Shashar N, Wieler U, Agiv H, Paris CB (2014) Polarized light sensitivity and orientation in coral reef fish post-larvae. PLOS ONE 9:e88468

*Bode M, Leis JM, Mason LB, Williamson DH, Harrison HB, Choukroun S, Jones GP (2019) Successful validation of a larval dispersal model using genetic parentage data. PLOS Biol 17:e3000380

Booth DJ (1992) Larval settlement pattern and preferences by domino damselfish, Dascyllus albisella Gill. J Exp Mar Biol Ecol 155:85-104

Botsford LW, White JW, Coffroth MA, Paris CB and others (2009) Connectivity and resilience of coral reef metapopulations in marine protected areas: matching empirical efforts to predictive needs. Coral Reefs 28:327-337

* Caley MJ, Carr MH, Hixon MA, Hughes TP, Jones GP, Menge BA (1996) Recruitment and the local dynamics of open marine populations. Annu Rev Ecol Evol Syst 27:477-500

* Catalano KA, Dedrick AG, Stuart MR, Puritz JB, Montes HR, Pinsky ML (2021) Quantifying dispersal variability among nearshore marine populations. Mol Ecol 30:2366-2377

Christie MR, Tissot BN, Albins MA, Beets JP and others (2010) Larval connectivity in an effective network of marine protected areas. PLOS ONE 5:e15715

* Christie MR, Miermans PG, Gaggioti OE, Toonen RJ, White C (2017) Disentangling the relative merits and disadvantages of parentage analysis and assignment tests for inferring population connectivity. ICES J Mar Sci 74: 1749-1762

Coleman RR (2019) Patterns of connectivity in three coral reef fishes across three spatial scales. PhD thesis, University of Hawaii, Honolulu

Coppock AG, González-Murcia SO, Srinivasan M, Gardiner NM, Jones GP (2020) Different responses of coral and rubble-dwelling coral reef damselfishes (Family: Pomacentridae) to chemosensory cues from coral reef microhabitats. Mar Biol 167:74

Cowen RK, Sponaugle S (2009) Larval dispersal and marine population connectivity. Annu Rev Mar Sci 1:443-466

Cowen RK, Paris CB, Srinivasan A (2006) Scaling of connectivity in marine populations. Science 311:522-527

Cowen RK, Gawarkiewicz G, Pineda J, Thorrold SR, Francisco EW (2007) Population connectivity in marine systems: an overview. Oceanography (Wash DC) 20:14-21

Dekshenieks MM, Hofmann EE, Powell EN (1993) Environmental effects on the growth and development of eastern oyster, Crassostrea virginica (Gmelin, 1791) larvae: a modeling study. J Shellfish Res 12:241-245
Dixson DL, Jones GP, Munday PL, Planes S and others (2008) Coral reef fish smell leaves to find island homes. Proc R Soc B 275:2831-2839

* Dixson DL, Abrego D, Hay ME (2014) Chemically mediated behavior of recruiting corals and fishes: a tipping point that may limit reef recovery. Science 345:892-897

Doherty PJ (1991) Spatial and temporal patterns in recruitment. In: Sale PF (ed) The ecology of fishes on coral reefs. Academic Press, San Diego, CA, p 261-293

Doherty PJ (2002) Variable replenishment and the dynamics of reef fish populations. In: Sale PF (ed) Coral reef fishes: dynamics and diversity in a complex ecosystem. Academic Press, San Diego, CA, p 327-358

Domeier ML, Colin PL (1997) Tropical reef fish spawning aggregations: defined and reviewed. Bull Mar Sci 60: 698-726

* Dower JF, Pepin P, Kim GC (2009) Covariation in feeding success, size-at-age and growth in larval radiated shanny (Ulvaria subbifurcata): insights based on individuals. J Plankton Res 31:235-247

W Durski SM, Glenn SM, Haidvogel DB (2004) Vertical mixing schemes in the coastal ocean: comparison of the level 2.5 Mellor-Yamada scheme with an enhanced version of the K profile parameterization. J Geophys Res C Oceans 109: C01015

* Egbert GD, Bennett AF, Foreman MG (1994) TOPEX/ POSEIDON tides estimated using a global inverse model. J Geophys Res 99:24821-24852

Faillettaz R, Paris CB, Irisson JO (2018) Larval fish swimming behavior alters dispersal patterns from marine protected areas in the north-western Mediterranean Sea. Front Mar Sci 5:97

Fox J, Weisberg S (2019) An R companion to applied regression, $3^{\text {rd }}$ edn. Sage Publications, Thousand Oaks, CA. https://socialsciences.mcmaster.ca/jfox/Books/Companion/

F Fox HE, Haisfield KM, Brown MS, Stevenson TC, Tissot BN, Walsh WJ, Williams ID (2012) Influences of oceanographic and meteorological features on reef fish recruitment in Hawai'i. Mar Ecol Prog Ser 463:259-272

*Frédérich B, Colleye O, Lepoint G, Lecchini D (2012) Mistmatch between shape changes and ecological shifts during the post-settlement growth of the surgeonfish, Acanthurus triostegus. Front Zool 9:8

Gaines SD, Gaylord B, Gerber LR, Hastings A, Kinlan BP (2007) Connecting places: the ecological consequences of dispersal in the sea. Oceanography (Wash DC) 20:90-99

Garrido S, Ben-Hamadou R, Santos AMP, Ferreira S and others (2015) Born small, die young: intrinsic, size-selective mortality in marine larval fish. Sci Rep 5:17065

*Gerlach G, Atema J, Kingsford MJ, Black KP, Miller-Sims V (2007) Smelling home can prevent dispersal of reef fish larvae. Proc Natl Acad Sci USA 104:858-863

*Gouezo M, Wolanski E, Critchill K, Fabricius K, Harrison P, Golbuu Y, Doropoulos C (2021) Modelled larval supply predicts coral population recovery potential following disturbance. Mar Ecol Prog Ser 661:127-145

*Green AL, Maypa AP, Almany GR, Rhodes KL and others (2015) Larval dispersal and movement patterns of coral reef fishes, and implications for marine reserve network design. Biol Rev Camb Philos Soc 90:1215-1247

*Gosberg RK, Levitan DR (1992) For adults only? Supplyside ecology and the history of larval biology. Trends Ecol Evol 7:130-133

*Hartig F (2021) DHARMa: Residual diagnostics for hierarchical (multi-level / mixed) regression models. R pack- 
age version 0.4.4. https://cran.r-project.org/web/packages/DHARMa/DHARMa.pdf

*Hixon MA, Anderson TW, Buch KL, Johnson DW, McLeod JB, Stallings CD (2012) Density dependence and population regulation in marine fish: a large-scale, long-term field manipulation. Ecol Monogr 82:467-489

*Hixon MA, Bowen BW, Coleman RR, Counsell CW and others (2022) Fish flow: following fisheries from spawning to supper. Front Ecol Environ, doi:10.1002/fee.2449

Hjort J (1914) Fluctuations in the great fisheries of northern Europe viewed in the light of biological research. Rapp P-V Reun Cons Int Explor Mer 20:1-228

Johnson DW, Christie MR, Pusack TJ, Stallings CD, Hixon MA (2018) Integrating larval connectivity with local demography reveals regional dynamics of a marine metapopulation. Ecology 99:1419-1429

Jones GP, Planes S, Thorrold SR (2005) Coral reef fish larvae settle close to home. Curr Biol 15:1314-1318

Kalinowski ST, Taper ML, Marshall TC (2007) Revising how the computer program CERVUS accommodates genotyping error increases success in paternity assignment. Mol Ecol 16:1099-1106

Kinlan BP, Gaines SD (2003) Propagule dispersal in marine and terrestrial environments: a community perspective. Ecology 84:2007-2020

Kraft DW, Conklin EE, Barba EW, Hutchinson M, Toonen RJ, Forsman ZH, Bowen BW (2020) Genomics versus mtDNA for resolving stock structure in the silky shark (Charcharhinus falciformis). PeerJ 8:e10186

Lecchini D, Waqalevu VP, Parmentier E, Radford CA, Banaigs B (2013) Fish larvae prefer coral above algal water cues: implications of coral reef degradation. Mar Ecol Prog Ser 475:303-307

Leis JM (2021) Perspectives on larval behavior in biophysical modelling of larval dispersal in marine, demersal fishes. Oceans 2:1-25

Leis JM, McCormick MI (2002) The biology, behavior, and ecology of the pelagic, larval stage of coral reef fishes. In: Sale PF (ed) Coral reef fishes: dynamics and diversity in a complex ecosystem. Academic Press, San Diego, CA, p 171-199

Longenecker K, Langston R (2008) Life history compendium of exploited Hawaiian fishes. Prepared for Fisheries Local Action Strategy and Division of Aquatic Resources, Honolulu, HI

Lowe RJ, Falter JL, Monismith SG, Atkinson MJ (2009) A numerical study of circulation in a coastal reef-lagoon system. J Geophys Res Oceans 114:C06022

Marshall TC, Slate J, Kruuk LE, Pemberton JM (1998) Statistical confidence for likelihood-based paternity inference in natural populations. Mol Ecol 7:639-655

Matthews D, Powell BS, Janeković I (2012) Analysis of fourdimensional variational state estimation of the Hawaiian waters. J Geophys Res Oceans 117:C03013

* McCormick MI (1999) Delayed metamorphosis of a tropical reef fish (Acanthurus triostegus): a field experiment. Mar Ecol Prog Ser 176:25-38

McLeod IM, Rummer JL, Clark TD, Jones GP, McCormick MI, Wenger AS, Munday PL (2013) Climate change and the performance of larval coral reef fishes: the interaction between temperature and food availability. Conserv Physiol 1:cot024

McManus MA, Woodson CB (2012) Plankton distribution and ocean dispersal. J Exp Biol 215:1008-1016

Metaxas A, Saunders M (2009) Quantifying the 'bio-' com- ponents in biophysical models of larval transport in marine benthic invertebrates: advances and pitfalls. Biol Bull (Woods Hole) 216:257-272

Michalakes J, Chen SH, Dudhia J, Hart L, Klemp JB, Middlecoff J, Skamarock W (2001) Development of a nextgeneration regional weather research and forecast model. In: Zieflhofer W, Kreitz N (eds) Developments in teracomputing. World Scientific, Singapore, p 269-276

* Mouritsen H, Atema J, Kingsford MJ, Gerlach G (2013) Sun compass orientation helps coral reef fish larvae return to their natal reef. PLOS ONE 8:e66039

*North EW, Schlag Z, Hood RR, Li M, Zhong L, Gross T, Kennedy VS (2008) Vertical swimming behavior influences the dispersal of simulated oyster larvae in a coupled particle-tracking and hydrodynamic model of Chesapeake Bay. Mar Ecol Prog Ser 359:99-115

North EW, Gallego A, Petitgas P (eds) (2009) Manual of recommended practices for modelling physical-biological interactions during fish early life. ICES Coop Res Rep 295

* Otwoma LM, Diemel V, Reuter H, Kochzius M, Meyer A (2018) Genetic population structure of the convict surgeonfish Acanthurus triostegas: a phylogeographic assessment across its range. J Fish Biol 93:597-608

* Paris CB, Cowen RK (2004) Direct evidence of a biophysical retention mechanism for coral reef fish larvae. Limnol Oceanogr 49:1964-1979

* Paris CB, Helgers J, van Sebille E, Srinivasan A (2013) Connectivity Modeling System: a probabilistic modeling tool for the multi-scale tracking of biotic and abiotic variability in the ocean. Environ Model Softw 42:47-54

Peck MA, Huebert KB, Llopiz JK (2012) Intrinsic and extrinsic factors driving match-mismatch dynamics during the early life history of marine fishes. Adv Ecol Res 47: 177-302

* Pelc RA, Warner RR, Gaines SD, Paris CB (2010) Detecting larval export from marine reserves. Proc Natl Acad Sci USA 107:18266-18271

* Petitgas P, Alheit J, Peck MA, Raab K and others (2012) Anchovy population expansion in the North Sea. Mar Ecol Prog Ser 444:1-13

* Pfeiffer-Herbert AS, McManus MA, Raimondi PT, Chao Y, Chai F (2007) Dispersal of barnacle larvae along the central California coast: a modeling study. Limnol Oceanogr 52:1559-1569

*Planes S, Jones GP, Thorrold SR (2009) Larval dispersal connects fish populations in a network of marine protected areas. Proc Natl Acad Sci USA 106:5693-5697

R Core Team (2019) R: a language and environment for statistical computing. R Foundation for Statistical Computing, Vienna

Randall JE (1956) A revision of the surgeonfish genus Acanthurus. Pac Sci 10:159-235

Randall JE (1961) A contribution to the biology of the convict surgeonfish of the Hawaiian Islands, Acanthurus triostegus sandvicensis. Pac Sci 15:215-272

Randall JE (1986) Acanthuridae. In: Smith MM, Heemstra PC (eds) Smiths' sea fishes. Springer-Verlag, Berlin, p 811-823

* Robertson DR (1983) On the spawning behavior and spawning cycles of eight surgeonfishes (Acanthuridae) from the Indo-Pacific. Environ Biol Fishes 9:193-223

Sale PF (1968) Influence of cover availability on depth preference of the juvenile manini, Acanthurus triostegus sandvicensis. Copeia 1968:802-807

* Sanvicente-Añorve L, Zavala-Hidalgo J, Allende-Arandía E, Hermoso-Salazar M (2018) Larval dispersal in three 
coral reef decapod species: influence of larval duration on the metapopulation structure. PLOS ONE 13: e0193457

Satterthwaite EV, Ryan JP, Harvey JBL, Morgan SG (2021) Invertebrate larval distributions influenced by adult habitat distribution, larval behavior, and hydrodynamics in the retentive upwelling shadow of Monterey Bay, California, USA. Mar Ecol Prog Ser 661: 35-47

Schemmel EM, Friedlander AM (2017) Participatory fishery monitoring is successful for understanding the reproductive biology needed for local fisheries management. Environ Biol Fishes 100:171-185

Schultz ET, Cowen RK (1994) Recruitment of coral-reef fishes to Bermuda: Local retention or long-distance transport? Mar Ecol Prog Ser 109:15-28

Schweigert JF, Boldt JL, Flostrand L, Cleary JS (2010) A review of factors limiting recovery of Pacific herring stocks in Canada. ICES J Mar Sci 67:1903-1913

Selkoe KA, Toonen RJ (2011) Marine connectivity: a new look at pelagic larval duration and genetic metrics of dispersal. Mar Ecol Prog Ser 436:291-305

Shchepetkin AF, McWilliams JC (2005) The Regional Oceanic Modeling System (ROMS): a split-explicit, free-surface,

Editorial responsibility: Myron Peck,

Den Burg, The Netherlands

Reviewed by: 3 anonymous referees topography-following-coordinate oceanic model. Ocean Model 9:347-404

Simpson SD, Meekan MG, Jeffs A, Montgomery JC, McCauley RD (2008) Settlement-stage coral reef fish prefer the higher-frequency invertebrate-generated audible component of reef noise. Anim Behav 75:1861-1868

* Swearer SE, Treml EA, Shima JS (2019) A review of biophysical models of marine larval dispersal. Oceanogr Mar Biol Annu Rev 57:325-356

Taylor MS, Hellberg ME (2003) Genetic evidence for local retention of pelagic larvae in a Caribbean reef fish. Science 299:107-109

Venables WN, Ripley BD (2002) Modern applied statistics with S, $4^{\text {th }}$ edn. Springer, New York, NY

*Vermeij MJA, Marhaver KL, Huijbers CM, Nagelkerken I, Simpson SD (2010) Coral larvae move toward reef sounds. PLOS ONE 5:e10660

Williamson DH, Harrison HB, Almany GR, Berumen ML and others (2016) Large-scale, multidirectional larval connectivity among coral reef fish populations in the Great Barrier Reef Marine Park. Mol Ecol 25:6039-6054

Zhou C, Chen Y (2014) Assimilation of GPS RO refractivity data and its impact on simulations of trade wind inversion and a winter cold front. Nat Sci 6:605-614

Submitted: April 9, 2021

Accepted: December 1, 2021

Proofs received from author(s): February 12, 2022 